\title{
IMPACT OF COGNITIVE PERFORMANCE ON THE FUNCTIONAL CAPACITY OF AN ELDERLY POPULATION IN NATAL, BRAZIL
}

\author{
Keithlen Cruz Moreira de Castro', Ricardo Oliveira Guerra²
}

\begin{abstract}
Functional incapacity and cognitive impairment are conditions related to the process of human aging. Cognitive impairment is considered an important predicitve factor for functional impairment in elderly populations. This cross-sectional study analyzes the association between cognitive performance and functional capacity in an elderly population sample in Natal, Brazil. A total of 213 elderly persons were assessed by the BOAS Multidimensional Questionnaire (Brazil Old Age Schedule) and the Mini-Mental State Examination (MMSE). The results of multivariate analysis and linear regression showed that age and schooling level are factors associated with cognitive performance in the elderly of this study. The final explicative model, elaborated by logistic regression, found that cognitive performance was the only predicitve variable of functional incapacity for the activities of daily living even when adjusted for sociodemographic variables.
\end{abstract}

KEY WORDS: MMSE, BOAS, elderly, functional status, cognitive impairment.

\begin{abstract}
Impacto do desempenho cognitivo na capacidade funcional em uma amostra populacional de idosos do nordeste brasileiro

Resumo - A incapacidade funcional e o déficit cognitivo são condições relacionadas com o processo de envelhecimento humano. O déficit cognitivo é considerado um importante fator preditor de prejuízos funcionais em populações idosas. Este estudo transversal analisa a associação do desempenho cognitivo na capacidade funcional de uma amostra populacional idosa residente em Natal-RN. Foram avaliados 213 idosos pelo Questionário Multidimensional-BOAS e pelo Mini-Exame do Estado Mental (MEEM). Através de analise multivariada mediante regressão linear, os resultados apontam a idade e o nível de escolaridade como fatores associados ao desempenho cognitivo nos idosos do estudo. O modelo explicativo final elaborado através de regressão logística apresentou o desempenho cognitivo como a única variável preditora de incapacidade funcional para as atividades da vida diária mesmo quando ajustado por variáveis sócio-demográficas.
\end{abstract}

PALAVRAS-CHAVE: MEEM, BOAS, idosos, status funcional, comprometimento cognitivo.

Functional dependence is one of the conditions related to the human aging process, and consequent decrease in the quality of life of elderly populations. Aspects such as advanced age, female sex, low schooling levels and comorbidity are strongly associated with functional dependency'. Functional capacity is influenced by demographic, socioeconomic, cultural and psychosocial factors ${ }^{2}$. Owing to the particular nature of detecting important impairments in elderly populations, functional capacity is increasingly seen by professionals as a new paradigm for assessing health in the elderly. Mental disturbances are common in elderly populations. It is estimated that $8 \%$ are afflicted by these pathologies ${ }^{3}$. The most important of these are dementias, because of their high frequency and the impact they cause on the health and functional capacity of this population ${ }^{4}$.

Mild cognitive impairment is characterized as the transitional state between normal aging and dementia, and is exemplified by abnormal memory loss for the age and schooling level of the individual, who otherwise exhibits no cognitive impairment ${ }^{5}$. In Brazil and other developing countries, population studies on dementia and cognitive impairment are scarce and there have been no precise estimates to date on their prevalence. A uniform prevalence

\footnotetext{
Department of Physical Therapy, Postgraduate Program in Health Sciences of the Federal University of Rio Grande do Norte (UFRN): 'Physical therapist, Masters student in Health Sciences, Postgraduate Program in Health Sciences; ${ }^{2}$ Professor, PhD Department of Physical Therapy at UFRN. Advisor of the Postgraduate Program in Health Sciences (UFRN). Study financed by the Foundation for Research Support of the State of Rio Grande do Norte (Project: 396 923507), Natal, Brazil.
}

Received 5 May 2008, received in final form 7 August 2008. Accepted 8 September 2008.

Dra. Keithlen Cruz Moreira de Castro - Rua Serra do Salitre 8000 - 59068-130 Natal RN - Brasil.E-mail: keithlen_cruz@yahoo.com.br 
of $3 \%$ is estimated, based on the prevalences of specific age groups observed in developed countries and according to the age distribution of the elderly population in developing countries ${ }^{6}$. Since cognitive impairment is an important health problem in elderly populations, owing to its interference in occupational and social functioning $^{2}$, epidemiological studies in developing countries are urgently needed, mainly in urban centers where a large number of elderly live under precarious socioeconomic conditions. These conditions are also observed in midsize Brazilian cities, as is the case of most capital cities in the northeast, including Natal.

Therefore, the aim of the present study was to analyze the impact of cognitive impairment on functional capacity in a population-based sample of elderly people living in Natal, Brazil.

\section{METHOD}

This cross-sectional study used an analytical and observational epidemiological design.

\section{Subject and location}

The study was conducted in Natal, capital city of the State of Rio Grande do Norte. The population-based sample consisted of elderly subjects of both sexes, older than 60 years of age, living in the western district of the city and enrolled in their neighborhood Family Health Program (FHP). Institutionalized individuals were not included in the study.

From a population of 14,597 residents in the western district older than 60 years of age (IBGE demographic census of 2000), we obtained a random sample of 213 subjects, taking into account a cognitive impairment frequency of $3 \%$, an error of $5 \%$ and a confidence level of $95 \%$.

\section{Measuring instruments}

To assess biological aspects and physical health we used the BOAS Multidimensional Questionnaire for Community studies in an Elderly Population, validated for Portuguese ${ }^{7,8}$. The questionnaire is divided into nine sections. These sections gather information on the main characteristics, needs and problems of an elderly population in a large urban center. Each specific section explores in depth the areas considered important because of their impact on the quality of life of the age group under study.

Functional capacity was assessed based on the activities of daily living (ADL), which were divided in the assessment protocol as follows: 6 items to assess the instrumental activities of daily living (IADL) and 8 items to evaluate the basic activities of daily living (BADL). Individuals that were unable to perform any one of the activities were considered to be functionally incapacitated.

To assess the cognition of the study group we used the MiniMental State Examination (MMSE), which is composed of questions typically grouped into 7 categories, each one designed to evaluate specific cognitive functions, such as orientation to time (5 points) and to place ( 5 points), recording 3 words to immediate memory ( 3 points), attention and calculation ( 5 points), recalling the 3 words ( 3 points), language (8 points), and constructive visual capacity (1 point). The MMSE score ranges from a minimum of 0 to a maximum of 30 points ${ }^{10}$.

\section{Procedures}

A group of trained researchers performed a pilot study before officially collecting the data, to determine if there were biases in subject selection and to verify the measurements of the instruments used. Data collection began after the reliability of the pilot study data was confirmed. The multidimensional questionnaire was applied, using interviews, to elderly residents of different neighborhoods of the western district of Natal. The participants or their legal caregivers signed an informed consent form and the project was approved by the Ethics Committee of the Federal University of Rio Grande do Norte (approval 08/2005).

Data analysis

The SPSS 12.0 statistical package was used to analyze the data. A descriptive analysis was performed for the frequency distri-

Table 1. Profile of the sample subjects according to sociodemographic characteristics, Natal, Brazil ( $n=213)$.

\begin{tabular}{|c|c|c|}
\hline Variables & $\begin{array}{l}\text { Absolute } \\
\text { frequency }\end{array}$ & $\begin{array}{l}\text { Relative } \\
\text { frequency }\end{array}$ \\
\hline \multicolumn{3}{|l|}{ Sex } \\
\hline Male & 64 & 30.0 \\
\hline Female & 149 & 70.0 \\
\hline Age $^{1}$ (years) & 213 & $70.2 \pm 7.8$ \\
\hline Male & 64 & $72.3 \pm 8.8$ \\
\hline Female & 149 & $69.3 \pm 7.1$ \\
\hline \multicolumn{3}{|l|}{ Color } \\
\hline White & 83 & 39.0 \\
\hline Mulatto & 102 & 47.9 \\
\hline Black & 27 & 12.7 \\
\hline No response & 1 & 0.4 \\
\hline \multicolumn{3}{|l|}{ Schooling (years) } \\
\hline Illiterate & 94 & 44.1 \\
\hline Some schooling & 119 & 55.9 \\
\hline \multicolumn{3}{|l|}{ Family income (month)* } \\
\hline$<1$ minimum wage & 83 & 39 \\
\hline$\geq 1<3$ minimum wages & 107 & 50.2 \\
\hline$\geq 3$ minimum wages & 16 & 7.5 \\
\hline No response & 7 & 3.3 \\
\hline \multicolumn{3}{|c|}{ Cognitive Function - MMSE (Score) ${ }^{1}$} \\
\hline Illiterate & 94 & $17.4 \pm 4.2$ \\
\hline Some schooling & 119 & $21.1 \pm 4.6$ \\
\hline \multicolumn{3}{|l|}{ Daily Activities } \\
\hline BADL dependency** & 14 & 6.6 \\
\hline AIDL dependency** & 30 & 14.1 \\
\hline
\end{tabular}


Table 2. Linear regression model between the Mini-Mental scores and functional capacity levels for developing $B A D L$ and IADL.

\begin{tabular}{lllcc}
\hline & & BADL dependency & \multicolumn{1}{c}{ IADL dependency } \\
\hline Spearman's Rho & MMSE SCORE & Correlation coefficient & $-.138\left(^{*}\right)$ & $-.214\left(^{* *}\right)$ \\
& & Sig. (bilateral) & .044 & .002 \\
& $\mathrm{~N}$ & 213 & 213 \\
\hline
\end{tabular}

${ }^{*} \mathrm{p}<0.05 ;{ }^{* *} \mathrm{p}<0.01$.

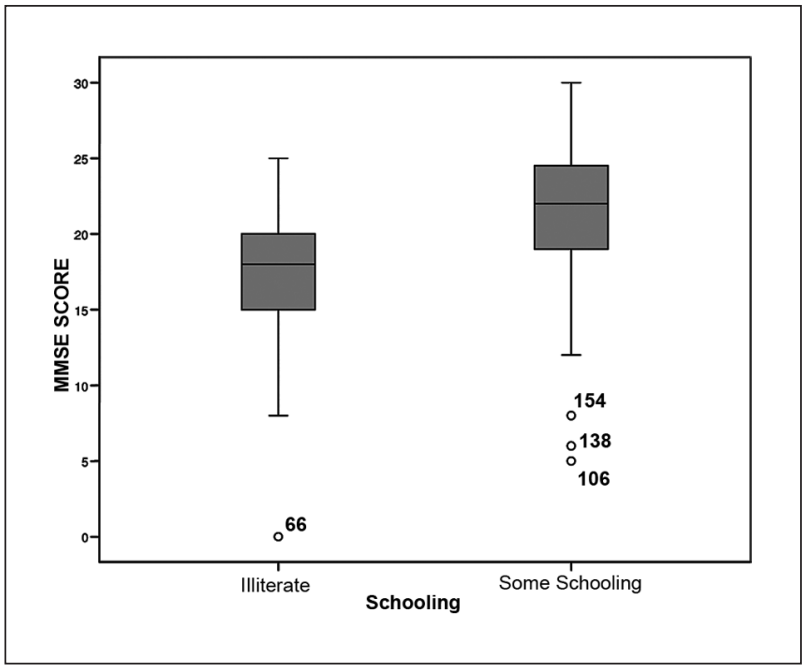

Fig 1. Distribution of Mini-Mental score according to schooling.

bution of the study variables. Spearman's correlation coefficient was used to analyze the association between MMSE scores and functional capacity levels. Using linear regression, we assessed the degree of predictive variable association with MMSE scores. An explicative model by logistic regression was used to evaluate the association between sociodemographic factors and cognitive function and functional incapacity for BADL and IADL. A significance level of $p<0.05$ was used for all the tests.

\section{RESULTS}

A total of 213 elderly persons were evaluated, 64 men (30.0\%) and 149 women (70.0\%). Mean overall age was $70.2 \pm 7.8$ years. The schooling level of the subjects was low; $45.5 \%$ were illiterate and only $14 \%$ had secondary or university education (Table 1).

Mean total MMSE score of the study subjects was $19.4 \pm 4.3$ points. After stratifying according to schooling level we observed a score median of 18 points for the illiterate subjects and 22 points for those with some level of schooling (Fig 1).

Functional incapacity for BADL and for IADL was observed in $6.6 \%$ and $14.1 \%$ of the subjects, respectively. Analyzing the functional incapacity for basic activities of daily living in relation to sex, we found a percentage of $6.3 \%$ for the men and $6.7 \%$ for the women.

A stratified analysis of the MMSE score according to

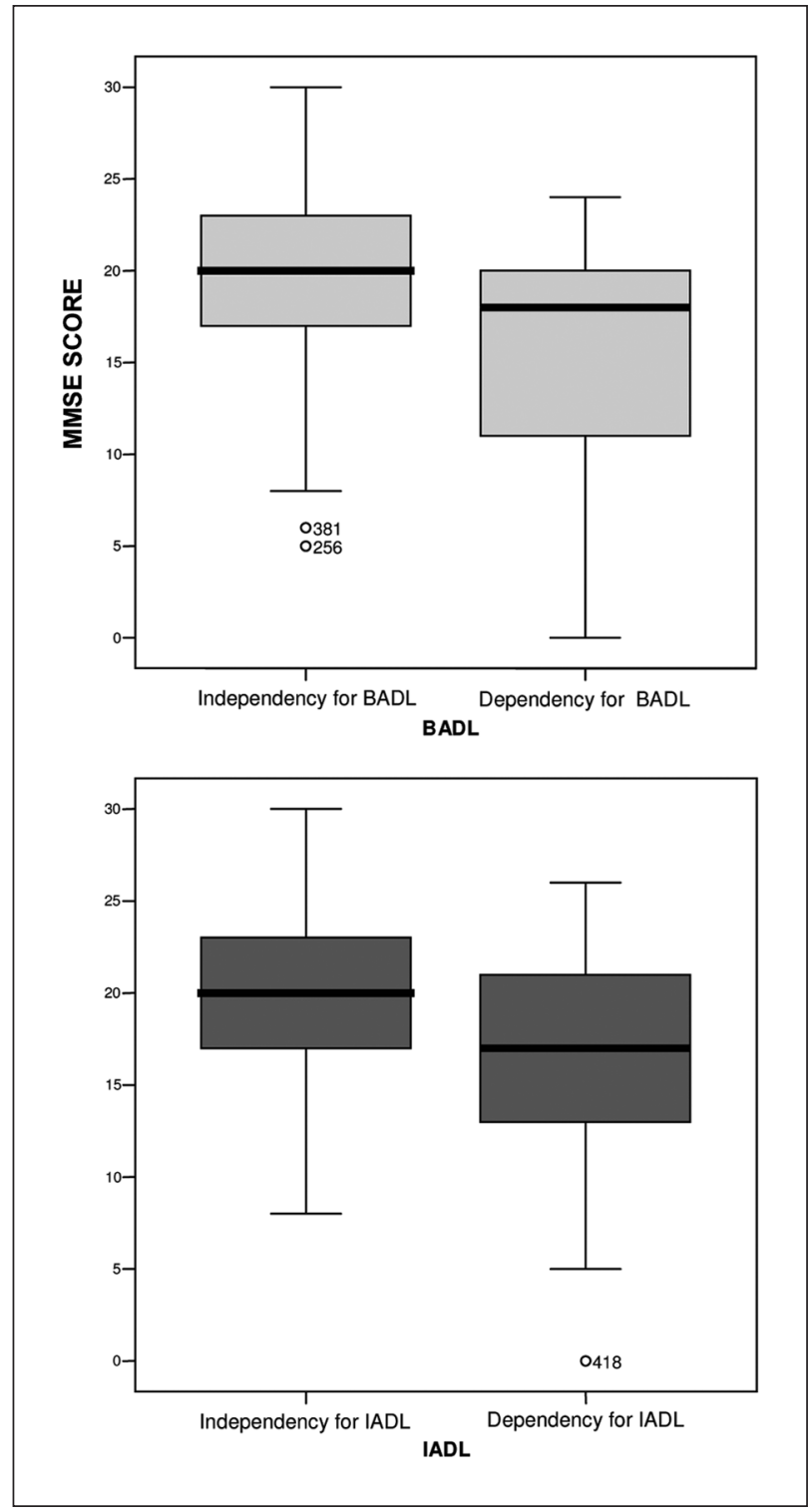

Fig 2. Frequency distribution of the Mini-Mental score stratified by level of functional dependency for basic and instrumental activities of daily living.

functional dependency scores for basic and instrumental ADL showed lower values in the elderly that had difficulty performing these activities (Fig 2).

Spearman's correlation values showed a negative coefficient between the MMSE score and the levels of func- 
Table 3. Final multiple linear regression model for the independent variables: age, sex, schooling, compared with the Mini-Mental score (Dependent variable).

\begin{tabular}{lccc}
\hline & $\mathrm{R}$ & Correlation coefficient & $\mathrm{P}$ \\
\hline Age & -0.141 & $-.220-(-.063)$ & 0.0001 \\
Sex & -0.443 & $-1.811-.924$ & 0.523 \\
Schooling (illiterate) & 3.746 & $2.532-4.960$ & 0.0001 \\
Color & -0.405 & $-1.286-.476$ & 0.366 \\
Marital state & -0.166 & $-.810-.477$ & 0.611 \\
Family income & 0.026 & $-.435-.486$ & 0.913 \\
\hline
\end{tabular}

$\mathrm{p}<0.05$.

tional capacity for developing BADL and IADL. This demonstrates that the lower the cognitive performance the higher the functional incapacity for ADL (Table 2).

To examine the possible associations of factors such as age, sex, color, marital status, family income, schooling level and functional capacity with cognitive performance, we developed an explicative model by multiple linear regression. Table 3 shows that age and schooling level were the only factors associated to cognitive performance in the elderly study subjects.

To determine the association of socioeconomic factors and cognitive performance with functional incapacity for the basic and instrumental ADL, we built an explicative model using logistic regression. In the final adjusted model, with functional incapacity as outcome variable, only the MMSE scores (cognitive performance) showed an association with the presence of incapacities for both types of activities (Table 4).

\section{DISCUSSION}

Recent studies show mild cognitive impairment (MCI) as an important predictive factor for functional impairment in elderly populations". It is therefore imperative to assess possible correlations between cognitive performance and the presence of functional impairment in developing the activities of daily living in less privileged populations. With respect to this aspect, the results of the present study strengthen the evidence of cognitive impairment as a strong factor associated with functional incapacity in poorly educated elderly populations.

A large number of elderly subjects reported little or no schooling. This finding, along with advancing age, were identified as the main determinants of cognitive performance levels in the population studied. Similar results were observed in earlier studies ${ }^{12,13}$. According to Laks ${ }^{14}$ and Foss ${ }^{15}$, both age and schooling influence cognitive performance, and people with higher schooling levels show, in an ascending hierarchy, better performance than those of less schooled.
Table 4. Odds ratio (OR) for functional capacity in BADL and $I A D L$ by the final logistic regression model.

\begin{tabular}{lccc}
\hline Variables & OR & Cl 95\% & $\mathrm{P}$ \\
\hline \multicolumn{4}{c}{ Basic activities of daily living } \\
MMSE score & 1.13 & $1.12-1.26$ & 0.021 \\
Sex & 1.12 & $0.31-4.07$ & 0.85 \\
Age & 1.03 & $0.93-1.07$ & 0.93 \\
Schooling & 1.46 & $0.44-4.86$ & 0.53 \\
Marital status & 1.08 & $0.59-1.97$ & 0.80 \\
Family income & 1.40 & $0.78-2.49$ & 0.25 \\
& Instrumental activities of daily living & \\
Variables & OR & Cl 95\% & $\mathrm{P}$ \\
MMSE score & 1.18 & $1.12-1.29$ & 0.0001 \\
Sex & 3.03 & $0.99-9.25$ & 0.85 \\
Age & 1.03 & $0.94-1.04$ & 0.81 \\
Schooling & 0.64 & $0.44-4.86$ & 0.53 \\
Marital status & 1.08 & $0.59-1.97$ & 0.80 \\
Family income & 1.40 & $0.78-2.49$ & 0.25 \\
\hline
\end{tabular}

$\mathrm{p}<0.05$.

The high illiteracy rate found in this study is compatible with the findings of other investigations on elderly Brazilian populations ${ }^{16,17}$. A large number of the subjects in our study scored less than 23 points on the MMSE. Score differences between the illiterate group and those with some schooling are comparable to those found in previous Brazilian studies ${ }^{12,14,16}$. In these cases, adjusting the MMSE score according to schooling level is indispensable in recognizing cognitive impairment in elderly population samples, where educational deficiencies are a constant reality. The influence of low schooling on neuropsychological evaluations shows that healthy elderly individuals with low schooling may be erroneously diagnosed as being cognitively impaired, or even demented ${ }^{15}$.

Longitudinal studies have proved that cognitive impairment promotes changes in the performance of activities 
of daily living ${ }^{11,18}$. The results of functional incapacity levels of the elderly studied here corroborate those reported in other community-based studies, showing significant differences between the level of dependence for the activities of daily living, when related to the MMSE score ${ }^{16,17}$. Given that our study is a cross-cut investigation, we are unable to confirm causal relationships. However our results suggest, based on the literature, that there is an inverse relation between cognitive performance and functional incapacity for the activities of daily living ${ }^{13,18}$, specifically for $I A D L$, where, owing to their complexity and interaction with the surrounding environment, elderly individuals need better cognitive performance to execute these tasks.

Among other implications, the findings of this study point to the need for effective cognitive impairment screening policies in elderly populations treated at public health posts. Preventive actions against the advance of cognitive impairment in elderly populations, through the use of pharmacological interventions such as vitamin B complex supplementation and the practice of physical activity, may be effective in preventing functional incapacities ${ }^{19}$.

The results of this study enable the formation of a cognitive performance profile of the elderly population living in Natal, Brazil. Identifying the factors associated to cognitive impairment may reduce the impact of these conditions on functional capacity, through the application of appropriate preventive measures.

\section{REFERENCES}

1. Graciani A, Banegas JR, Lopez-Garcia E, Rodriguez-Artalejo F. Prevalence of disability and associated social and health-related factors among the elderly in Spain: a population-based study. Maturitas 2004; 48:381-392.

2. Rosa TED, Benicio MHD, Latorre MD, Ramos LR. Determinant factors of functional status among the elderly. Rev Saude Publica 2003;37: 40-48.
3. Maia LC, Durante AM, Ramos LR. [Prevalence of mental disorders in an urban area in Brazil]. Rev Saude Publica 2004;38:650-656.

4. Lopes MA, Bottino CM. Prevalence of dementia in several regions of the world: analysis of epidemiologic studies from 1994 to 2000. Arq Neuropsiquiatr 2002;60:61-69.

5. Fontan-Scheitler LE, Lorenzo-Otero J, Silveira-Brussain A. Disorder profile in the Mini-Mental State Examination in patients with mild cognitive impairment. Rev Neurol 2004; 39:316-321.

6. Scazufca M, Cerqueira AT, Menezes PR,et al. Epidemiological research on dementia in developing countries. Rev Saude Publica 2002;36:773-778.

7. George LK, Fillenbaum GG. OARS methodology. A decade of experience in geriatric assessment. J Am Geriatr Soc 1985;33:607-615.

8. Veras RP, Coutinho E, Ney GJ. The elderly population in Rio de Janeiro (Brazil): a pilot-study of confiability and validity of the mental health segment of the BOAS questionnaire. Rev Saude Publica 1990;24:156-163.

9. Paixao CM Jr, Reichenheim ME. A review of functional status evaluation instruments in the elderly. Cad Saude Publica 2005;21:7-19.

10. Almeida OP. Mini mental state examination and the diagnosis of dementia in Brazil. Arq Neuropsiquiatr 1998;56:605-612.

11. Dodge HH, Kadowaki T, Hayakawa T, Yamakawa M, Sekikawa A, Ueshima H. Cognitive impairment as a strong predictor of incident disability in specific ADL-IADL tasks among community-dwelling elders: the Azuchi study. Gerontologist 2005;45:222-230.

12. Brito-Marques PR, Cabral-Filho JE. The role of education in mini-mental state examination: a study in Northeast Brazil. Arq Neuropsiquiatr 2004;62:206-211.

13. Laks J, Batista EM, Guilherme ER, et al. Prevalence of cognitive and functional impairment in community-dwelling elderly: importance of evaluating activities of daily living. Arq Neuropsiquiatr 2005;63:207-212.

14. Laks J, Batista EM, Guilherme ER, et al. Mini-mental state examination in community-dwelling elderly: preliminary data from Santo Antonio de Padua, Rio de Janeiro, Brazil. Arq Neuropsiquiatr 2003;61:782-785.

15. Foss MP, Vale FA, Speciali JG. Influence of education on the neuropsychological assessment of the elderly: application and analysis of the results from the Mattis Dementia Rating Scale (MDRS). Arq Neuropsiquiatr 2005;63:119-126.

16. Feliciano AB, Moraes SA, Freitas IC. Low-income senior citizens in the Municipality of São Carlos, Sao Paulo State, Brazil: an epidemiological survey. Cad Saude Publica 2004;20:1575-1585.

17. Maia LC, Durante AM, Ramos LR. Prevalence of mental disorders in an urban area in Brazil. Rev Saude Publica 2004;38:650-656.

18. Artero S, Touchon J, Ritchie K. Disability and mild cognitive impairment: a longitudinal population-based study. Int J Geriatr Psychiatry 2001;16:1092-1097.

19. Van Uffelen JG, Hopman-Rock M, Chin APM, Van MW. Protocol for Project FACT: a randomised controlled trial on the effect of a walking program and vitamin B supplementation on the rate of cognitive decline and psychosocial wellbeing in older adults with mild cognitive impairment [ISRCTN19227688]. BMC Geriatr 2005;5:18. 